\title{
Changes in the behaviour of a male Eurasian badger: evidence in favour of the anti-kleptogamy hypothesis?
}

\author{
Eloy REVILLA and Francisco PALOMARES
}

\begin{abstract}
Revilla E. and Palomares F. 1999. Changes in the behaviour of a male Eurasian badger: evidence in favour of the anti-kleptogamy hypothesis? Acta Theriologica 44: 471-476.

We report a case of male badger Meles meles (Linnaeus, 1758) territorial expansion after the removal, by poaching activity, of a neighbouring male in an area of low badger density. The most plausible reason for the behaviour of this male is the gaining of the access to the females of the adjacent territory because: the male spent approximately half of his active time inside the new area, made a similar effort as the previous male in sleeping together with the new breeding female and did not use the summer-autumn feeding areas of the taken range. While considering that data have come from only one animal, it is discussed the key importance of female access against food resources and shelter when explaining male badger spatial behaviour, at least in low density populations.
\end{abstract}

Estación Biológica de Doñana, CSIC; Avenida de Maria Luisa s/n, Pabellón del Perú, 41013 Sevilla, Spain, fax: -34-5-4621125, e-mail: revilla@cica.es

Key words: Meles meles, male territoriality

\section{Introduction}

Territoriality has been explained as a response to competition for one or more basic resources such as food, shelter or access to females (Clutton-Brock 1989). Two competing hypotheses have been proposed to explain male territoriality in the Eurasian badger Meles meles (Linnaeus, 1758): (1) territoriality is directed towards defending oestrus females, ie the anti-kleptogamy hypothesis (Roper et al. 1986, Roper and Lüps 1993, Roper et al. 1993), and (2) territoriality is a means of defending patches of the staple food, ie the resource dispersion hypothesis (Kruuk 1978, Macdonald 1983, Woodroffe and Macdonald 1993). Kruuk and Macdonald (1985) suggested that evidence in favour of one or the other hypothesis may be gained through the experimental removal of one or more males in a badger population. In this case, the anti-kleptogamy hypothesis would predict that the male vacant territory would be taken over by a neighbouring male in order to gain access to the new free female/s, whereas under the resource dispersion hypothesis it would be expected that the neighbouring males would not change their space use, or all members (including females) of the neighbouring groups would use the new free food patches in the vacant area. Such a test of the hypotheses has not been carried out, however, (but see Roper and Lüps 1993), because of the ethical problems in undertaking the removal of males for this propose (Cuthill 1991). 
In this study, we report the change in male space use that occurred after the involuntary removal (by poaching activity) of an adult territorial male badger in south-western Spain.

\section{Material and methods}

The study was carried out in south-west Spain in the north of Donana National Park (Coto del Rey), an area with degraded Mediterranean cork woods Quercus suber surrounded by marshes, pine plantations Pinus pinea, and small streams (Fig. 1). The soil is sandy except for marshes, where it is clay. In Coto del Rey, badgers live in small territorial groups (for more information about this population see Revilla 1998, and about other Mediterranean populations see Martín et al. 1995, Rodriguez et al. 1996).

Badgers were trapped with box-traps and leg-hold traps and fitted with radio-transmitters following conventional techniques (Cheeseman and Mallinson 1980). Marked animals were located daily on foot in their diurnal resting sites and at least three times per week during the night using triangulation. For the purpose of this study, we used radiotracking information from two territories, A at the north and B at the south (453 and 808 ha respectively, Revilla 1998), from January 1995 to July 1996. The number of animals per territory was obtained through the radiotracking data combined with direct observations at setts and track censuses after periods of intensive continuous radiotracking of all the marked animals from the same territory. All the home range analyses were defined as the minimum convex polygon at $90 \%$, centred on the harmonic mean, in order to minimize inter-territorial overlapping and to avoid excursions, using the RANGESV software package (Kenward and Hodder 1996). The study population feeds on rabbits and fruits (Revilla 1998).

\section{Results}

Before the death of the male (MB1, Table 1), there were clearly two different adjacent territories. Territory 'A' had a radio-marked adult male (MA1) and an unmarked adult breeding female (FA1), who produced two cubs in 1996, one of which was radiotracked (FA2, Table 1). Territory ' $\mathrm{B}$ ' had an adult male (MB1), a breeding female (FB1) and a two-years-old non-breeding female (FB2), all of them radio-tracked (Table 1). FB1 produced one cub in 1995. MB1 was killed by poachers on 15 August 1995 (Table 1).

Table 1. Age, radiotracking periods, cause of failure and number of radiolocations before (left side) and after (right side) the death of MB1, of the Eurasian badgers, Meles meles, under study. Code for the animals: M - males, F- females, A - 'A' territory, B - 'B' territory. ${ }^{*}$ - seen still inside B territory on 22 June 1996.

\begin{tabular}{lllllcr}
\hline Animal & Age & $\begin{array}{l}\text { Beginning of } \\
\text { tracking }\end{array}$ & End of tracking & Cause & $\begin{array}{l}\text { Number of } \\
\text { radiolocations }\end{array}$ \\
\hline MA1 & adult & 20 January 1995 & 30 March 1996* & collar failure & 261 & 214 \\
FA2 & cub & 30 May 1996 & 20 August 1996 & collar loss & - & 83 \\
MB1 & adult & 01 January 1995 & 15 August 1995 & killed by poachers & 30 & - \\
FB1 & adult & 10 April 1995 & 21 June 1996 & killed by poachers & 170 & 379 \\
FB2 & subadult & 22 July 1995 & 10 October 1995 & killed by poachers & 28 & 70 \\
\hline
\end{tabular}


Before MB1's death, home ranges largely overlapped between the B male and B females $(91.0 \%$ for FB1 and $36.0 \%$ for FB2), while the overlap between the males' ranges was, on average, only $12.4 \%$ (Fig. 1). MB1 and FB1 slept together in the same sett on $30.2 \%$ of the days that both animals were located resting $(n=116)$ and on $52.4 \%$ of days with FB2 $(n=21)$. Before MB1's death, MA1 was active within the 'B' territory only the $15.5 \%$ of 58 independent night locations.

After MB1's death, MA1's home range was $48.3 \%$ greater than his previous one. His new home range overlapped $46.0,43.0$ and $33.0 \%$ of the home ranges of FA2 (ie his previous female), FB1 and FB2 (ie his new females; see below), respectively (Fig. 2). Between northern and southern females, however, there was a low home range overlap (eg $12.0 \%$ between FA2 and FB1; Fig. 2).

MA1 slept for the first time inside territory B on 24 September 1995 (40 days after MB1's death). Since then, MA1 slept within the former territory B setts on $50.4 \%$ of days ( $n=123$ daylight locations). He slept together with FB1 and FB2 on $36.2 \%(n=116)$ and $25.0 \%(n=12)$ of days, respectively. There is no significant difference between the previous effort of MB1 and the one of MA1 in sleeping

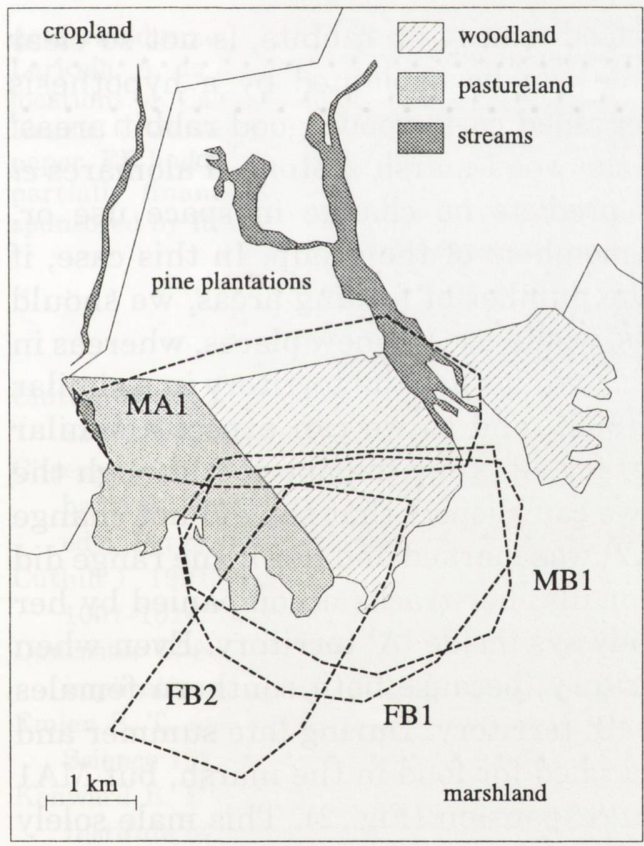

Fig. 1. Home ranges of all marked Eurasian badgers, Meles meles, before the 15 August 1995, when animal MB1 was killed by poachers. 'A' territory at the north and ' $\mathrm{B}$ ' territory at the south of the figure. More information about the animals' code in Table 1.

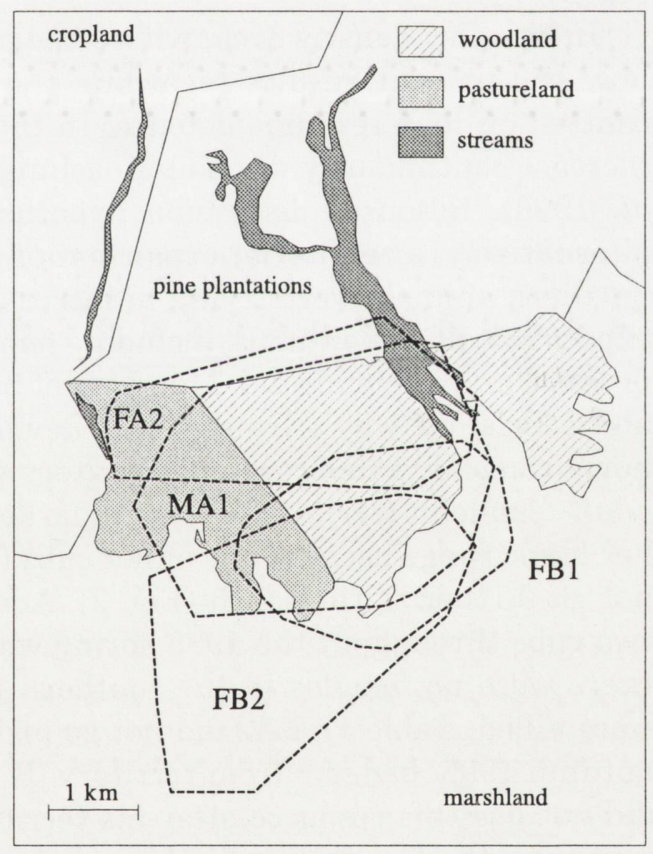

Fig. 2. Home ranges of all the marked Eurasian badgers, Meles meles, after the 15 August 1995, when animal MB1 was killed by poachers. ' $A$ ' territory at the north and ' $\mathrm{B}$ ' territory at the south of the figure. More information about the animals' code in Table 1. 
together with FB1 $\left(\chi^{2}=0.70, \mathrm{df}=1, p=0.403\right)$. Sixty-seven percent of 58 independent nocturnal active locations of MA1 were inside the former territory B.

\section{Discussion}

Despite the fact that our results concern only one male removal, we believe that trying to explain them within the actual contextual knowledge is an interesting exercise. Results concerning male territoriality seem to better fit the anti-kleptogamy hypothesis than the resource dispersion hypothesis, both of which have been used to explain male territoriality in badgers. Competition for shelter and its availability have also been used to explain male territoriality in mammals (Clutton-Brock 1989) and group territoriality in badgers (Doncaster and Woodroffe 1993). However, potential resting setts in our study area are extremely abundant, so they are not expected to be limiting. In the study area badgers use rabbit warrens as setts (Revilla 1998), and the density of warrens ranges from 2 to 12 per hectare (Palomares et al. 1996). Potential availability of setts is such that, for example, MA1, MB1, FB1 and FB2 used 50 different setts during a single year (1995).

In this low density area, where badgers feed mainly on rabbits, is not so clear how the present results regarding the male can be explained by a hypothesis centred on food resource defence. In the degraded cork wood, 'good rabbit areas' increase continuously when approaching to the wood-marsh ecotone (Palomares et al. 1996). Resource dispersion hypothesis predicts no change in space use or, alternatively, a territorial expansion of all members of the group. In this case, if northern animals were trying to increase the number of feeding areas, we should expect that all the animals, including females, would use the new places, whereas in practice only the male did. Members of badger groups use the territory in a similar and consistent way (Kruuk 1989, Revilla 1998), and so we can expect a similar home range size (approaching territory size) for all group members. Although the adult female in territory A was unmarked, we can suspect that she did not change her home range because one of her cubs (FA2) was marked and her home range did not go further to the south (Fig. 2). Additionally, her tracks accompanied by her two cubs throughout the 1996 spring were always inside 'A' territory. Even when there were no females in the southern territory (because both southern females were killed, Table 1), FA2 did not go inside 'B' territory. During late summer and autumn 1995, badgers from territory 'B' searched for food in the marsh, but MA1 did not use this resource after his territorial expansion (Fig. 2). This male solely took over the forested area where setts are located and where finding the resting females seems easier. All these observations seem to indicate that the male interest was not in the feeding areas, despite the fact that he could also forage in the new range.

The fact that MA1 was the new male of the southern females was shown by his effort in sleeping with the southern females and by the time spent inside the 
southern territory, expending more than half of his nocturnal active time. This second observation, with more time spent in the taken area, can be explained because in the southern part there was two females and not only one, as in the northern range (without considering the cub). The most reasonable explanation for this behaviour is that the male was taking the neighbouring territory in order to ensure mating access to the ' $\mathrm{B}$ ' females. For this animal the new larger territory means a greater effort in defence, because it must keep contact with all the females for not loosing the access to them (Emlen and Oring 1977). Even in areas with high badger density, a similar territorial expansion occurred in a case of traumatic death of all male members of one group (Roper and Lüps 1993). These look like a behavioural adaptation to increase male individual fitness.

In our study, the male badger seemed to behave as solitary carnivores where male space use is influenced by female spacing patterns and accessibility (male main resource), while female distribution depends on food dispersion (female main resource; Powell 1979, Sandell 1989). Badgers have been considered as a 'contractionist species' (Kruuk and Macdonald 1985), but the present study shows that in at least some conditions, males can behave as 'expansionist', increasing the size of the individual home range to gain new females.

Acknowledgements: We want to thank to the following persons and institutions: V. Salvatori, G. Lariccia, A. de Jong, L. Polderman, A. Devenoges and M. Rodriguez did part of the diurnal badger locations. J. Calzada and J. Ayala helped with trapping and night locations. T. Roper, M. Delibes, H. Kruuk, G. Janss, P. Ferreras and two anonymous referees did helpful comments on first drafts of this paper. ER had a predoctoral grant from the Spanish Ministry of Education and Science. This study was partially financed by the Spanish C.I.C.Y.T. (project numbers PB94-0480 and PB97-1163) and sponsored by Rover España.

\section{References}

Clutton-Brock T. H. 1989. Mammalian mating systems. Proceedings of the Royal Society of London B 236: 339-372.

Cheeseman C. L. and Mallinson P. J. 1980. Radio tracking in the study of bovine tuberculosis in badgers. [In: A handbook of biotelemetry and radio tracking. C. J. Amlaner and D. W. Macdonald, eds]. Pergamon Press, Oxford: 649-656.

Cuthill I. 1991. Field experiments in animal behaviour: methods and ethics. Animal Behaviour 42 : $1007-1014$.

Doncaster C. P. and Woodroffe R. 1993. Den site can determine shape and size of badgers territories: implications for group living. Oikos 66: 88-93.

Emlen S. T. and Oring L. W. 1977. Ecology, sexual selection and the evolution of mating systems. Science 197: 215-223.

Kenward R. E. and Hodder K. H. 1996. Ranges V. An analysis system for biological location data. Institute of Terrestrial Ecology, Wareham: 1-66.

Kruuk H. 1978. Spatial organisation and territorial behaviour of the European badger Meles meles. Journal of Zoology, London 184: 1-19.

Kruuk H. 1989. The social badger. Ecology and behaviour of a group-living carnivore (Meles meles). Oxford University Press, Oxford: 1-155.

Kruuk H. and Macdonald D. W. 1985. Group territories of carnivores: empires and enclaves. [In: Behavioral ecology: ecological consequences of adaptative behaviour. R. M. Sibly and R. H. Smith, eds]. Blackwell Scientific Publications, Oxford: 521-536. 
Macdonald D. W. 1983. The ecology of carnivore social behavior. Nature 301: 379-384.

Martín R., Rodríguez A. and Delibes M. 1995. Local feeding specialization by badgers (Meles meles) in a Mediterranean environment. Oecologia 101: 45-50.

Palomares F., Calzada J. and Revilla E. 1996. El manejo del hábitat y la abundancia de conejos: diferencias entre dos áreas potencialmente idénticas. Revista Florestal 9: 201-210.

Powell R. A. 1979. Mustelid spacing patterns: variations on the theme by Mustela. Zeitschrift für Tierpsychology 50: 153-165.

Revilla E. 1998. Organización social del tejón en Doñana. Ph D thesis, University of León, León: 1-222.

Rodríguez A., Martín R. and Delibes M. 1996. Space use and activity in a mediterranean population of badgers Meles meles. Acta Theriologica 41: 59-72

Roper T. J., Conradt L., Butler J., Christian S. E., Ostler J. J. and Schmid T. K. 1993. Territorial marking with faeces in badgers (Meles meles): a comparison of boundary and hinterland latrine use. Behaviour 127: 287-307.

Roper T. J. and Lüps P. 1993. Disruption of territorial behaviour in badgers Meles meles. Zeitschrift für Säugetierkunde 58: 252-255.

Roper T. J., Shepherdson D. J. and Davies J. M. 1986. Scent marking with faeces and anal secretion in the European badger (Meles meles): seasonal and spatial characteristics of latrine use in relation to territoriality. Behaviour 97: 94-117.

Sandell M. 1989. The mating tactics and spacing patterns of solitary carnivores. [In: Carnivore behavior, ecology, and evolution. J. L. Gittleman, ed]. Chapman and Hall, London Vol. 1: 164-182.

Woodroffe R. and Macdonald D. W. 1993. Badger sociality-models of spatial grouping. Symposia of the Zoological Society of London 65: 145-169.

Received 27 March 1998, accepted 2 April 1999. 